\title{
Ileal interposition with sleeve gastrectomy for treatment of type 2 diabetes
}

\author{
Alper Çelik \\ Metabolic Surgery Clinic, Istanbul, Turkey
}

\begin{abstract}
Metabolic syndrome and 2 of its most important components, obesity and type 2 diabetes, have reached pandemic proportions threatening the entire world. Initial treatment options directed at life style changes, including diet and exercise, have failed to achieve desired results for an important portion of patients and status of considerable number of patients has eventually become worse than pre-treatment due to reactive weight regain. Currently, the most effective treatment for obesity and type 2 diabetes is, without doubt, surgical procedure. There is no treatment option that can achieve remission for all of the components of metabolic syndrome with over $90 \%$ efficiency. However, it should be known that there are numerous methods used for surgical treatment of metabolic syndrome, and all have advantages, disadvantages, and restrictions of their own. Also, each has its own rate of efficiency. Aim of this article was to provide a brief understanding of mechanisms of action and to analyze outcomes of diverted sleeve gastrectomy with ileal transposition as functional restrictive therapeutic option for obese and non-obese patients with type 2 diabetes.
\end{abstract}

Keywords: Ileal transposition; metabolic surgery; sleeve gastrectomy.

\section{Metabolic Surgery}

The original description of metabolic surgery is "the treatment of any metabolic disease by surgical means". In this respect, splenectomy used for the treatment of hematological disorders like ITP, Idiopathic Thrombocytopenic Purpura, is accepted within the concept of metabolic surgery. However, when metabolic surgery is mentioned in clinical practice, what is meant is the treatment of non-morbidly obese type 2 diabetic patients with surgical procedures. To this end, the only surgical method applied to overweight type 2 diabetic patients from the start has been ileal transposition (IT). ${ }^{[7,8]}$ However, recent popular approach is to adapt obesity surgery procedures like gastric bypass to overweight patients and name them as "Metabolic Surgery". The purpose of this article was to discuss surgical procedures with specific emphasis on IT and review possible solutions against probable scenarios awaiting us in the future.

\section{"Functional Restriction" and Surgical Success}

Currently, the most widespread procedures in obesity surgery are gastric bypass and sleeve gastrectomy. Unfortunately, the third most widespread procedures in terms of frequency are revision operations. Sadly, the word "re- 
vision" represents the disability and inefficiency of the operations performed. Just like any other field in surgery, obesity surgery also has a learning curve of its own and it is obvious that the reason of insufficient weight loss/ weight regain problems occurring within the first year after surgery is technical incompetency. However, long term follow-up results of the patients who have undergone gastric banding or sleeve gastrectomy prove that the main problem reveals itself five years after surgery and one third of those patients require revision or additional surgical intervention. ${ }^{[9-12]}$ Gastric band is entirely a restrictive operation. Sleeve gastrectomy is a restrictive procedure even though it causes changes in some digestive system hormones. Any restriction on human kind fails eventually. Therefore, it comes as no surprise that restrictive surgical procedures fail as well. Surgical community should bear in mind that the most important criteria for long term success is to activate ileum based anorexigenic hormones (GLP-1, Peptide YY, Oxyntomodulin, and etc.) and to achieve this without causing malabsorption. What counts as surgical success is not mechanical restriction provided by a little pouch, tight anastomosis or narrow sleeve gastrectomy, but "Functional Restriction" achieved by the activation of satiety hormones since the feeling of hunger can be sated with hormones such as GLP-1, Peptide YY and oxyntomodulin which are secreted when food enters distal ileum. Members of the entire surgical community serving in the field of metabolic and bariatric surgery should focus on activating these hormones by surgical means without causing malabsorption.

\section{Which Operation?}

There are two published methods based upon this goal, which are ileal transposition (IT) and transit bipartition (TB) procedures. Both operations are performed laparoscopically together with a sleeve gastrectomy in order to reduce ghrelin levels, avoid peptic ulcers, decrease caloric intake and avoid gastric dilation. ${ }^{[13]}$ However, these techniques utilize different strategies. IT maximizes distal gut activity interposing a segment of ileum right after the stomach and minimizes proximal activity excluding the duodenum. ${ }^{[7,8]} \mathrm{TB}$ enhances distal activity bringing the whole ileum to the antrum and diminishes proximal activity shifting food from the duodenal route, which is left intact, further minimizing malabsorption (and amplifying endoscopic access, instead of reducing it). Both procedures aim at functional (and not the mechanical) restriction, trying to avoid malabsorption, instead of having it as a beneficial goal.

\section{lleal Transposition: A Challenging Option?}

IT associated with a diverted sleeve gastrectomy has been blamed for its complexity and named as a challenging operation. However, recently published evidence suggest that IT, compared to sleeve and bypass, has a slightly higher, but acceptable complication (6.1\%) and mortality $(0.27 \%)$ rates, and can be safely performed within the hands of well trained and dedicated teams. ${ }^{[14]}$

\section{Ileal Transposition: Do We Really Need IT?}

IT with diverted sleeve gastrectomy technique offers the possibility to provide us caloric restriction, duodenal exclusion and enhanced early ileal stimulation, without significant malabsorption, which makes the IT operation different from BPD and DS where the entire jejunum is bypassed (Figure 1). BPD and DS do have the capability to provide same opportunities with the expense of a marked malabsorption. Surgeons should question the extent of the consequences of daily clinical practice and keep away from ending one form of addiction, while triggering another one. Since only proximal $50 \mathrm{~cm}$ of the jejunum is bypassed in IT, the technique provides this facility without causing a marked malabsorption. Preoperative and postoperative analysis of patients undergoing IT has demonstrated that iron deficiency anemia and vitamin D deficiency dropped from $6.7 \%$ and $24.2 \%$ to $6.1 \%$ and $19.7 \%$, respectively. ${ }^{[14]}$

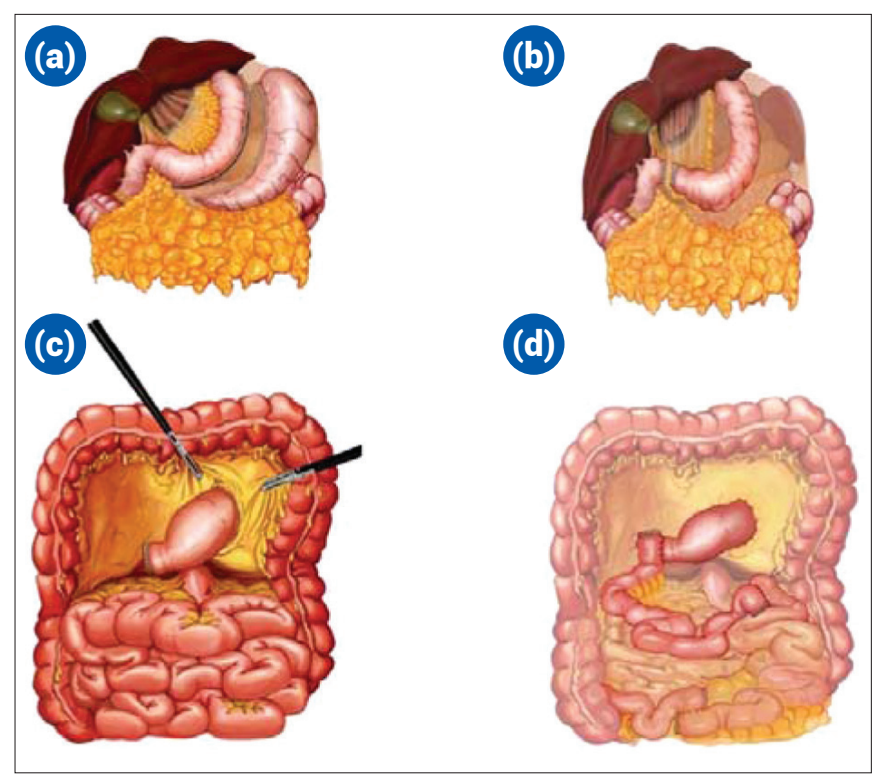

Figure 1. Schematic demonstration of the operation. (a) Sleeve gastrectomy. (b) Duodenal transection. (c) Inframesocolic transfer of the sleeve. (d) Interposition of the ileal segment between distal stomach and the proximal jejunum. 
Table 1. Mechanisms involved in the occurrence and progression of type 2 diabetes

1. Inadequate insulin release from beta cells, disrupted early phase insulin effect

2. Insulin resistance (IR) in peripheral tissues

3. Increased endogenous glucose production (hepatic/intestinal glucose output)

4. Adipocytes

5. Gastrointestinal tractus (incretion insufficiency/ resistance)

6. Alpha cell (hyperglucagonemia)

7. Kidney (glucose reabsorption)

8. CNS (insulin resistance-others)

\section{Pathophysiology of Type 2 Diabetes and IT}

Type 2 diabetes is a dynamic, heterogeneous and multifactorial disease. In the novel paper by Ralph De Fronzo, eight mechanisms have been pointed out for the development and progression of type 2 diabetes, which are shown in Table 1. In morbidly obese diabetics, the excess fat (adipotoxicity) takes the central place, whereby in nonmorbidly obese individuals, beta cell failure associated insulin insufficiency and disrupted insulin release plays the central effect. In other words, in morbidly obese diabetics, the main problem is insulin resistance, and in non-morbidly obese individuals, the main denominators of surgical success are insulin sensitivity and beta cell

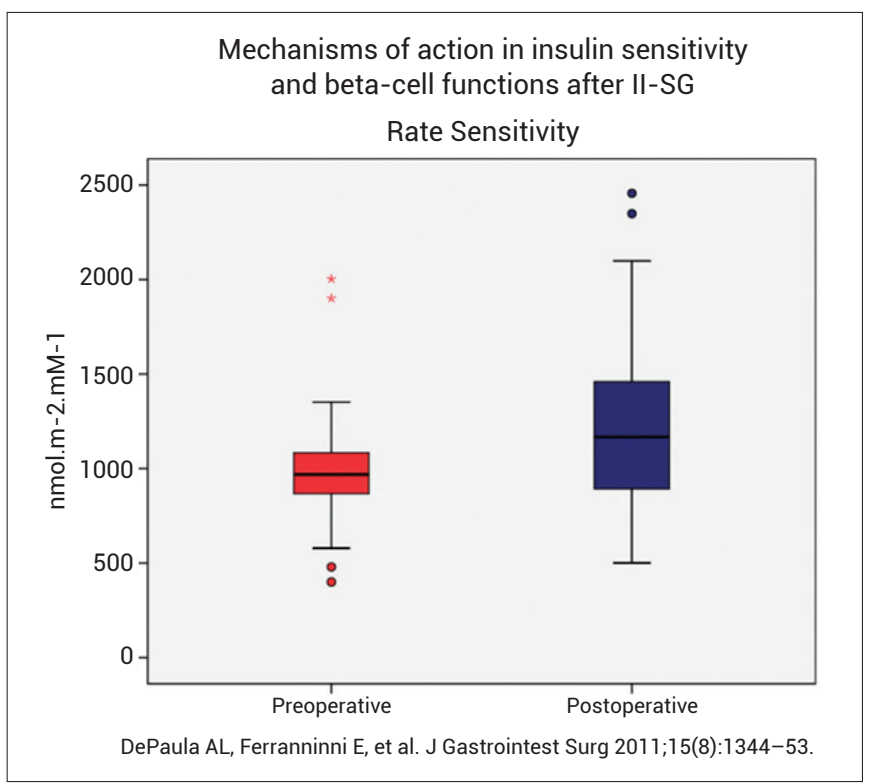

Figure 2. Changes in rate sensitivity after IT. glucose sensitivity. From this point of view, clamp studies can guide with respect to disease pathophysiology ${ }^{[16,17]}$

\section{Clamp Studies}

\section{Insulin Sensitivity}

Insulin sensitivity in clamp method is calculated as the whole body insulin-mediated glucose uptake (M value, mol.min-1.kgffm-1) during the last forty min of the clamp normalized to fat-free mass. 6,6-2 [H5] glucose (titrated glucose) data is analyzed to calculate glucose rates of appearance ( $\mathrm{Ra}$ ) and disappearance (Rd) in the fasting state and during the clamp. Endogenous glucose production (EGP) is obtained as the difference between the timecourse of Ra and exogenous glucose infusion rate.

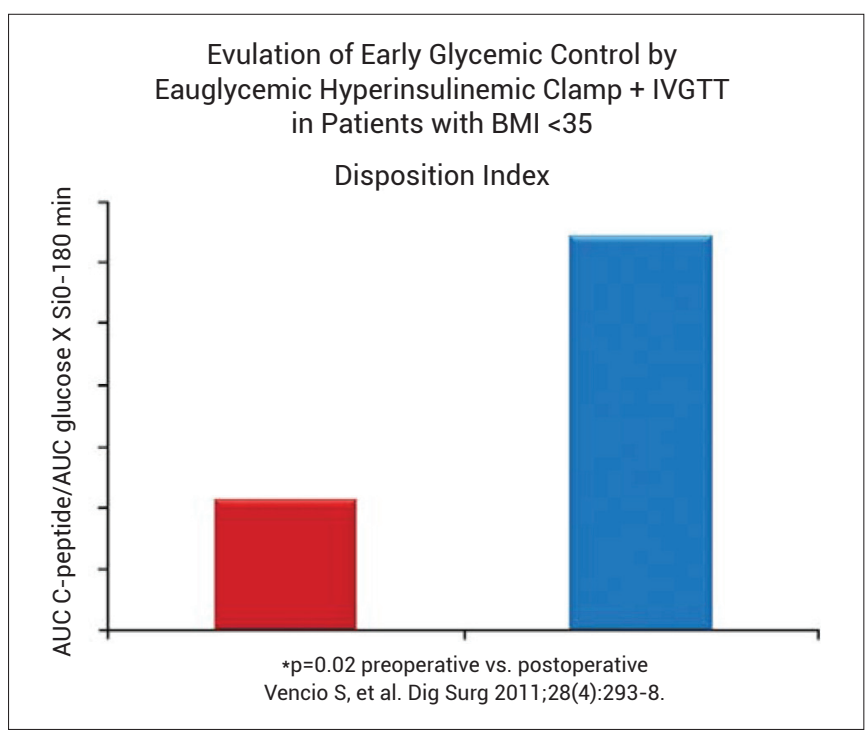

Figure 3. Changes in disposition index after IT.

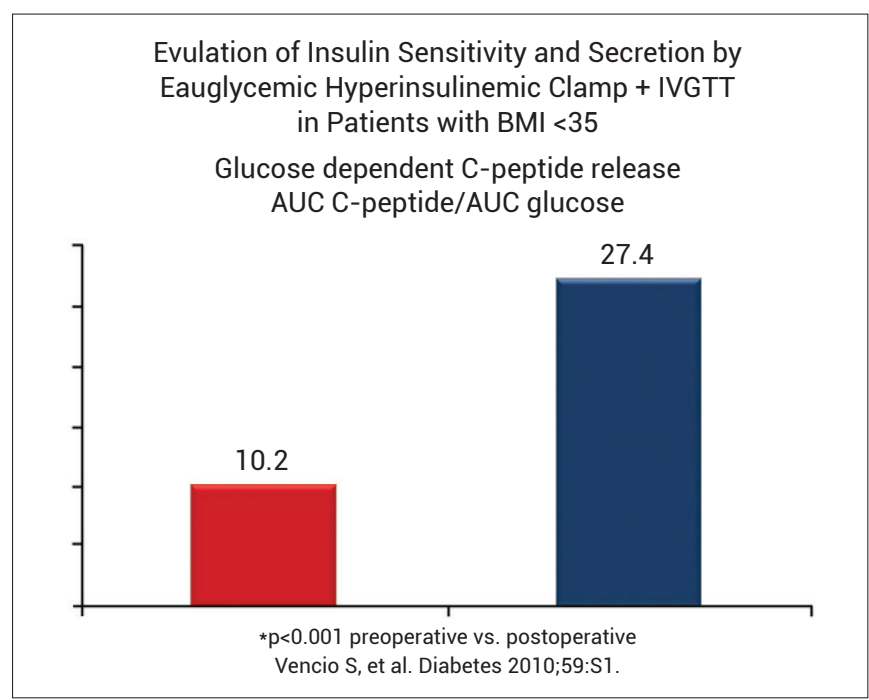

Figure 4. Changes in glucose dependent C-peptide release after IT. 


\section{Beta-Cell Function}

Beta-cell function during MTT is resolved using a mathematical model describing the relationship between insulin secretion and glucose concentration. In brief, the model consists of three blocks: firstly, glucose concentration profile is stabilized; secondly, dependence of insulin (or Cpeptide) secretion on glucose concentration is stabilized; and thirdly, C-peptide kinetics are individually adjusted to the subject's anthropometric data.

\section{Insulin Kinetics \& Efficiency}

The dependence of insulin secretion rate on absolute

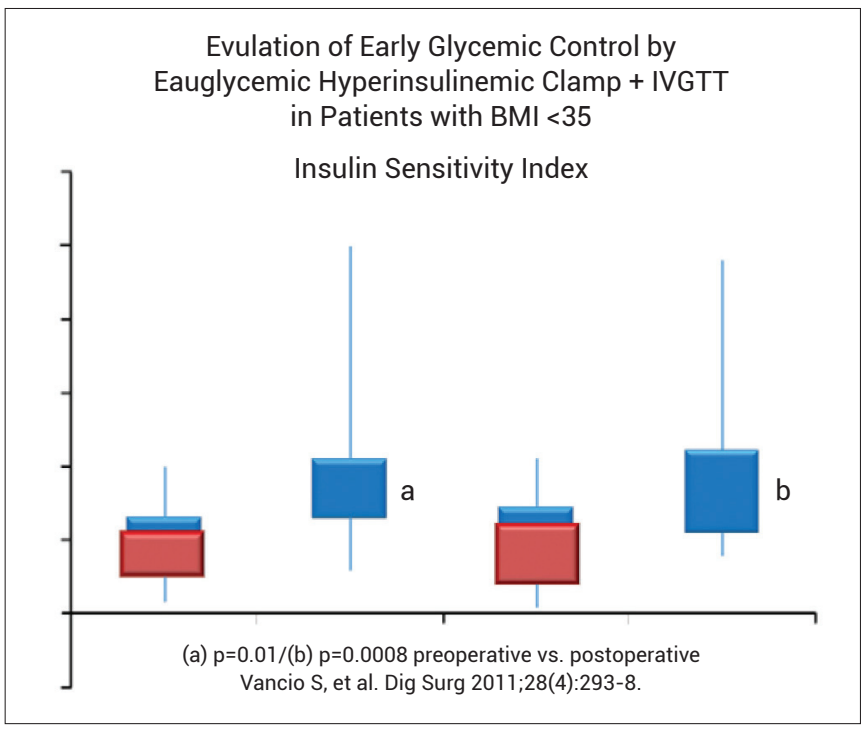

Figure 5. Changes in insulin sensitivity after IT.

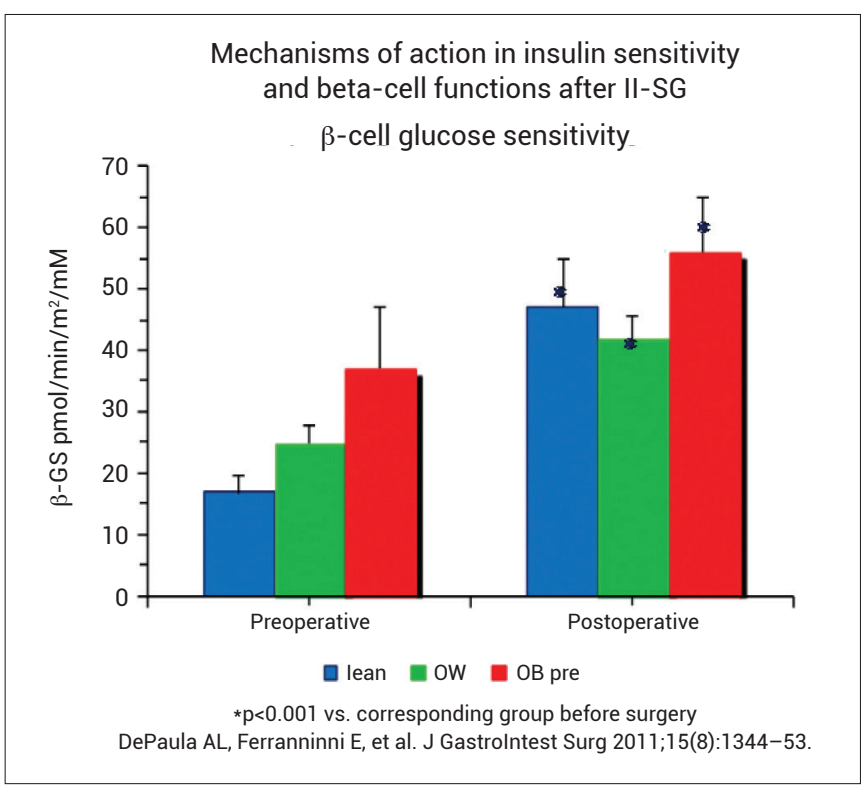

Figure 6. Changes in beta-cell glucose sensitivity in lean, overweight and obese patients after IT. glucose concentration at each time point during MTT is described by a dose-response function relating the two variables. The main characteristic parameter of the doseresponse, the mean slope within the observed glucose range, is denoted as beta-cell glucose sensitivity by analogy with insulin sensitivity (slope of the dose-response of insulin-mediated glucose uptake vs. insulin concentrations). The dose-response function is modulated by a timedependent potentiation factor, indexed as the ratio of its value at $2 \mathrm{~h}$ into the MTT to the corresponding basal value. The dependence of insulin secretion rate on the rate of change of plasma glucose levels is denoted as rate sensitivity.

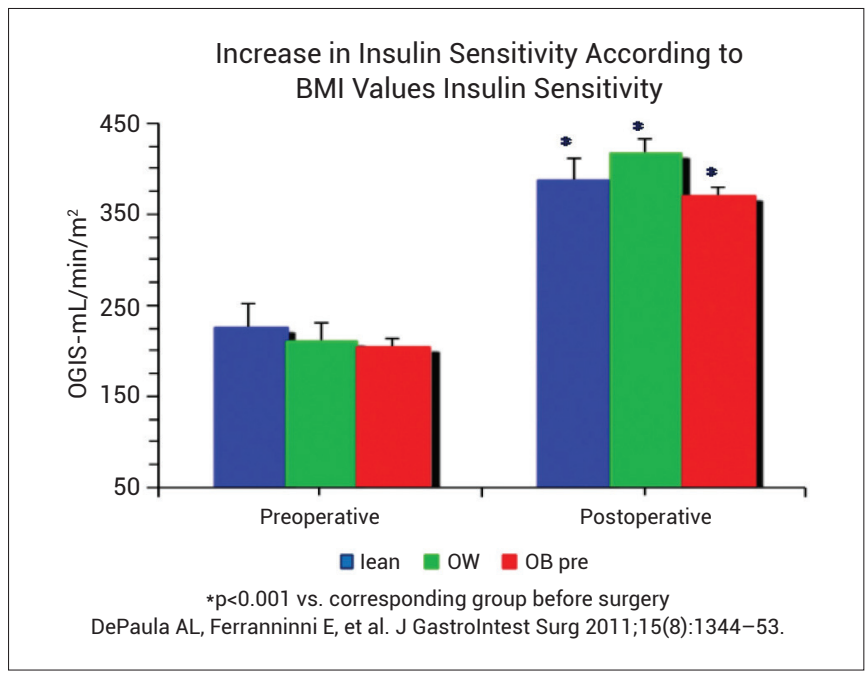

Figure 7. Changes in insulin sensitivity in lean, overweight and obese patients after IT.

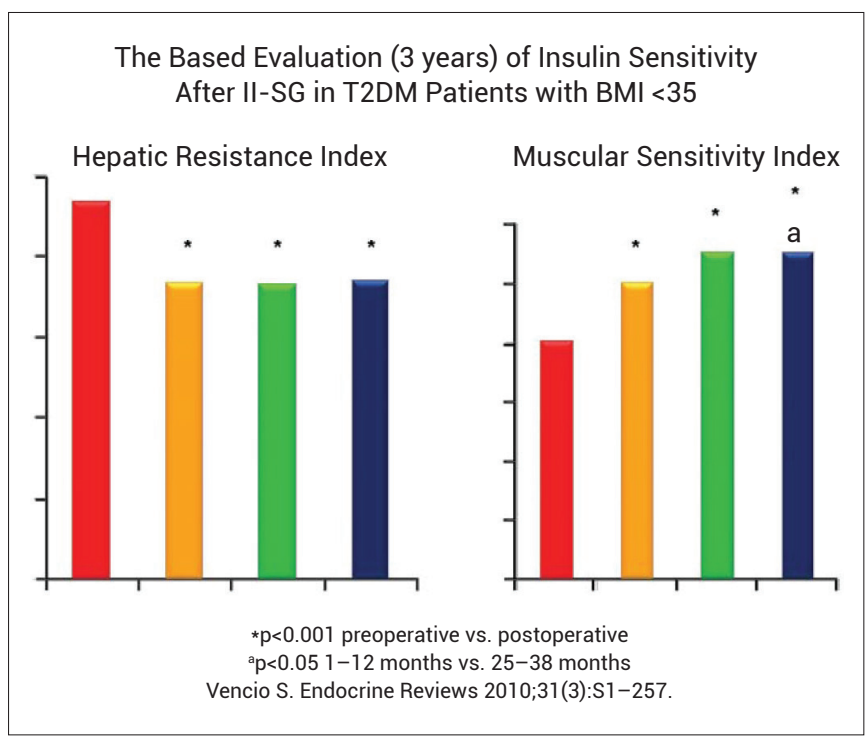

Figure 8. Changes in hepatic resistance index (left) and muscular sensitivity index (right) in lean, overweight, obese and morbidly obese patients after IT. 


\section{Mechanisms of Action in IT}

It has been previously documented that IT is associated with significant increase in rate sensitivity, disposition index, glucose dependent C-peptide release, and insulin sensitivity index (Figures 2-5). Furthermore, IT leads to significant elevations in beta cell glucose sensitivity, insulin sensitivity, hepatic resistance index, and muscular sensitivity index (Figures 6-8).

\section{Weight Loss}

IT operation has been performed on a wide variety of patients with BMI ranging from 25 to $>40 \mathrm{~kg} / \mathrm{m}^{2}$. Therefore, weight loss after IT has been evaluated in terms of BMI ranges. Briefly, patients were grouped into four categories: BMI $25-30,30-35,35-40$ and $>40 \mathrm{~kg} / \mathrm{m}^{2}$. Change in BMI according to these groups were $6.27,7.91,10.41$, and $13.2 \mathrm{~kg} / \mathrm{m}^{2}$ and percentage of excess BMI loss (EBMIL\%) was $22.4,24.64,27.98$, and $30.3 \%$, respectively. ${ }^{[14]}$ These data demonstrate that the more the preoperative excess weight, the more weight loss has been achieved by IT operation. This operation provides an early contact of ingested nutrients to the interposed distal ileum and an early and significant rise of glucagon-like peptide is observed. This step corrects the defective early phase of insulin secretion and leads to prolonged satiety.

\section{Summary}

Bariatric and Metabolic Surgery is still an evolving concept and there will always be a search for "the best" technique. Although BPD and DS provide the highest rates of remission in terms of weight control and glycemic regulation, they are still being practiced by less than 3\% of the bariatric community since these techniques require a life-long multi drug supplementation and may eventually necessitate a revisional surgery. Theoretical steps of success in the field of Bariatric \& Metabolic Surgery are listed below: ${ }^{[7,8,18]}$

1. Caloric restriction and weight adjustments

2. Increased gastric emptying and decreased Ghrelin levels

3. Early contact of the "non-digested" food with the ileal mucosa and "ileal nutrient sensing"

4. Correction of glucose dependent insulin response due to GIP effect (Duodenal Exclusion)

5. Correction of the glucagon suppression (Duodenal Exclusion + Ileal Proximalisation)
6. Decrease in hepatic and peripheral insulin resistance

7. Decrease in Hepatic Glucose Output

Data demonstrated in the present paper documents that IT operation provides all the above mentioned steps without causing long term malabsorption and supplement requirement. The major problem associated with IT is its technical difficulty and complexity which can be overcomed by wellorganized education and training models.

\section{References}

1. American Diabetes Association. The dangerous toll of diabetes. http://www.diabetes.org/diabetes-statistics/dangerous-toll.jsp.

2. Vaag AA. Glycemic control and prevention of microvascular and macrovascular disease in the Steno 2 study. Endocr Pract 2006;12 Suppl 1:89-92.

3. Bermudez DM, Pories WJ. New technologies for treating obesity. Minerva Endocrinol 2013;38:165-72.

4. Schauer PR, Kashyap SR, Wolski K, Brethauer SA, Kirwan JP, Pothier $\mathrm{CE}$, et al. Bariatric surgery versus intensive medical therapy in obese patients with diabetes. N Engl J Med 2012;366:1567-76.

5. Buchwald $H$, Estok R, Fahrbach $K$, Banel D, Jensen MD, Pories WJ, et al. Weight and type 2 diabetes after bariatric surgery: systematic review and meta-analysis. Am J Med 2009;122:248-56.

6. Vetter ML, Cardillo S, Rickels MR, Iqbal N. Narrative review: effect of bariatric surgery on type 2 diabetes mellitus. Ann Intern Med 2009;150:94-103.

7. De Paula AL, Stival AR, Halpern A, DePaula CC, Mari A, Muscelli $E$, et al. Improvement in insulin sensitivity and $\beta$-cell function following ileal interposition with sleeve gastrectomy in type 2 diabetic patients: potential mechanisms. J Gastrointest Surg 2011;15:1344-53.

8. DePaula AL, Stival AR, DePaula CC, Halpern A, Vencio S. Surgical treatment of type 2 diabetes in patients with BMI below 35: mid-term outcomes of the laparoscopic ileal interposition associated with a sleeve gastrectomy in 202 consecutive cases. J Gastrointest Surg 2012;16:967-76.

9. Swenson DW, Pietryga JA, Grand DJ, Chang KJ, Murphy BL, Egglin TK. Gastric band slippage: a case-controlled study comparing new and old radiographic signs of this important surgical complication. AJR Am J Roentgenol 2014;203:10-6.

10. Balogh J, Vizhul A, Dunkin BJ, Tariq N, Sherman V. Clinical management of patients presenting with non-adjustable gastric band (NAGB) complications. Yale J Biol Med 2014;87:159-66.

11. de Gara CJ, Karmali S. The anatomy of a weight recidivism and revision bariatric surgical clinic. Gastroenterol Res Pract 2014;2014:721095.

12. Kindel $T$, Martin E, Hungness E, Nagle A. High failure rate of 
the laparoscopic-adjustable gastric band as a primary bariatric procedure. Surg Obes Relat Dis 2014;10:1070-5.

13. Santoro S, Castro LC, Velhote MC, Malzoni CE, Klajner S, Castro LP, et al. Sleeve gastrectomy with transit bipartition: a potent intervention for metabolic syndrome and obesity. Ann Surg 2012;256:104-10.

14. Celik A, Ugale S, Ofluoglu H, Asci M, Celik BO, Vural E, et al. Technical feasibility and safety profile of laparoscopic diverted sleeve gastrectomy with ileal transposition (DSIT). Obes Surg 2015;25:1184-90.

15. Defronzo RA. Banting Lecture. From the triumvirate to the ominous octet: a new paradigm for the treatment of type 2 diabetes mellitus. Diabetes 2009;58:773-95.
16. Mari A, Gastaldelli A, Natali A, Ostergard T, Schmitz O, Ferrannini $E$. Characterization of beta-cell function impairment in first-degree relatives of type 2 diabetic subjects: modeling analysis of 24-h triple-meal tests. Am J Physiol Endocrinol Metab 2005;288:E541-6.

17. Van Cauter E, Mestrez F, Sturis J, Polonsky KS. Estimation of insulin secretion rates from $\mathrm{C}$-peptide levels. Comparison of individual and standard kinetic parameters for C-peptide clearance. Diabetes 1992;41:368-77.

18. Breen DM, Rasmussen BA, Kokorovic A, Wang R, Cheung GW, Lam TK. Jejunal nutrient sensing is required for duodenal-jejunal bypass surgery to rapidly lower glucose concentrations in uncontrolled diabetes. Nat Med 2012;18:950-5. 